\title{
Sweeter times ahead for sugarbeet growers
}

\author{
Stephen Kaffka and Peggy G. Lemaux
}

It is a rare day when results exceed even a hopeful researcher's expectations. In this issue, Hall et al. ${ }^{1}$ have had such a day. They report a striking breakthrough in the molecular manipulation of sugarbeets, which have been one of the most recalcitrant plant species to molecular methodologies: few germplasm lines have been amenable to transformation, transformation efficiencies have been extremely low, and the growth and development of transgenic plants have been slow and variable. Apparently, Hall et al. have overcome all three of these limitations by identifying an appropriate totipotent cell type and developing an optimized transformation protocol. They suggest that their method may have application to other important recalcitrant crop species as well, but it will be enough if they have contributed to the ease of transforming sugarbeet, one of

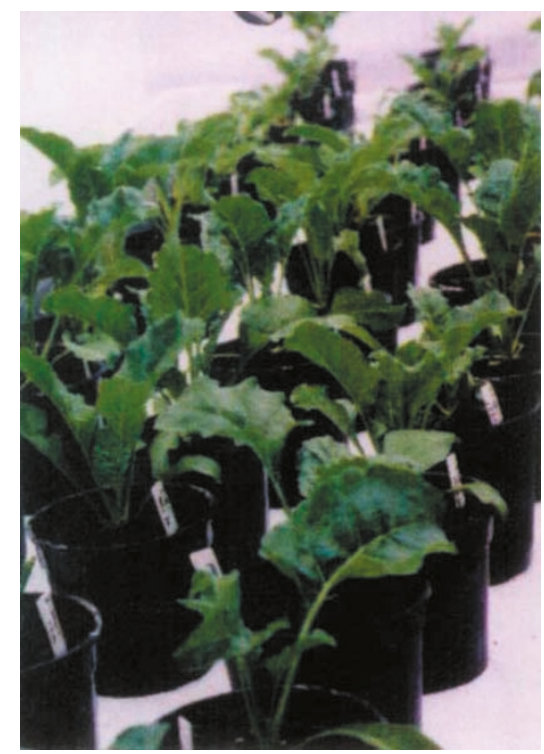

Sugar beet, a major source of sugar in temperate regions. the world's most important food crops.

Worldwide, sucrose consumption accounts for approximately $11 \%$ of human caloric intake ${ }^{2}$. Among the poor in many countries, the percentage is higher. In temperate and mediterranean regions of the world, sugarbeets are grown for sucrose, whereas sugarcane is used in tropical regions. About $40 \%$ of the world sugar supply is derived from beets. The extraction of sugar from beets was first undertaken in Germany in the late 18th century, but larger scale sugar production was stimulated in Europe only when the English struck directly at the French sweet tooth with a naval blockade during the Napoleonic Wars. Now, sugarbeets are one of the mainstays of European field crop production systems and

Stephen Kaffka is extension agronomist at the Department of Agronomy and Range Science, University of California, Davis 95616-8515 (srkaffka@ucdavis.edu) and Peggy G.Lemaux is extension specialist at the Department of Plant Biology, University of California,

Berkeley, CA 94720-3102

(lemauxpg@nature.berkeley.edu). are also produced in the former Soviet Union, North America, North Africa, Turkey, Iran, Pakistan, China, Japan, and Chile ${ }^{3}$.

Despite widespread production, sugarbeets (Beta spp.) can be a difficult crop to grow. Especially in warmer regions, a number of fungal, but especially viral, diseases such as rhizomania and beet yellows virus (BYV) can be severe. Crop establishment is always challenging because of sugarbeet's characteristic small seed size and low seedling vigor, the numerous pathogens, vertebrate and invertebrate pests attacking seedlings, and the relatively low plant populations needed for optimum yield compared, for example, with grain crops. There is less allowance for error. In California, where the world's highest farm yields have been achieved (19.1 tonnes of sucrose per hectare), the industry is in a slow decline because of decadeslong yield stagnation, attributable in part to the diverse effects of chronic, aphid-borne viruses on planting and harvesting periods. Besides direct yield losses, the need to identify and introgress resistance to multiple pathogens and pests severely constrains the rate of progress of classical plant breeding programs. When numerous resistance traits are necessary (many of which have low heritability and are multigenic and additive), genetic drag becomes significant. In some instances (e.g., BYV), there are limited naturally occurring resistance traits in the Beta genome.

Sugarbeet is a naturally cross-pollinating biennial and modern genotypes are very heterozygous (many are polyploid). Hybrids require three distinct germplasm lines to be produced and maintained ${ }^{5}$. Progress using classic plant breeding is slow at best. Molecular biology has had obvious potential to overcome some of the inherent difficulties involved in using classic breeding methods with sugarbeets, but the use of molecular methods has been slower to develop in beets than in many other crops such as cotton, rapeseed, soybean, maize, and tomatoes. The primary reason is that sugarbeets have been highly resistant to transformation efforts. Efficiencies have been so low in practice that candid remarks like "the production of a useful transformant seems like a random event" have been heard. Low transformation efficiency has greatly increased the cost and slowed the progress of molecular breeding of sugarbeets. Successfully transformed beets seem to be slow to develop, requiring up to two years to produce seed. Additionally, few genotypes have been amenable to transformation and many of those have poor agronomic characteristics.

Now, these constraints appear to have been overcome. Hall et al. report that they can transform sugarbeets at much greater rates than before. Guard cell protoplasts are the key to improved transformation efficiency. The identification and isolation of totipotent guard cells is apparently reproducible and the population sufficiently uniform to allow the development of an effective and replicable transformation protocol. Development is rapid, taking place in $8-9$ weeks, where previously months were required. Also significantly, they report success with most of the initial germ plasm used, including commercial cultivars. Happily, the system exceeds the hopes of its developers.

The work of Hall et al. represents a significant breakthrough for the sugarbeet crop and perhaps for other recalcitrant crops as well. We can look forward to more rapid development of cultivars with disease resistance and yield traits that might otherwise take one or more decades to develop, if at all, relying on classic breeding methods alone. This will greatly improve the overall efficiency of sugar production from beets. In California, for example, resistance to previously vexing viral diseases would allow farmers to better use sugarbeets in farming systems challenged by salinity and boron accumulation in soils, and water limitations, for which the crop is otherwise well suited.

1. Hall, R.D. et al. 1996. Nat. Biotechnol. 14:1133-1138.

2. Hawker, J.S. 1985. Sucrose, pp. 1-51, in Biochemistry of Storage Carbohydrates in Plants, Dey, P.M., and Dixon, R.A. (eds.). Academic Press, New York.

3. Kaffka, S. and Hills, F.J. 1994. Sugarbeet, pp. 215-223, in Encyclopedia of Agricultural Sciences, Vol. 4. Academic Press, New York.

4. Kaffka, S., and Lemaux, P.G. 1996. The Use of Molecular Breeding Methods to Advance the Sugarbeet Industry in California. (Spec. Pub. No. 21544.) Division of Agriculture and Natural Resources, University of California, Oakland.

5. Bosemark, N.O. 1993. Genetics and breeding, pp. 66-119, in The Sugarbeet Crop. Cooke, D.A., and Scott, R.K. (eds.). Chapman and Hall, Cambridge. 